\title{
Dimensões da urbanização dispersa e proposta metodológica para estudos comparativos: uma abordagem socioespacial em aglomerações urbanas brasileiras*
}

\author{
Ricardo Ojima**
}

\begin{abstract}
Este artigo procura abordar a urbanização brasileira sob uma perspectiva comparativa, a partir da construção de um Indicador de Dispersão Urbana, visando contribuir na análise dos desafios para uma urbanização sustentável. Trata-se da busca de evidências que confirmem as proposições teóricas de uma nova etapa do desenvolvimento da sociedade moderna (riscos socioambientais) e os desafios para análise da relação população-ambiente nos contextos urbanos. Para compor um indicador sintético de dispersão urbana para as aglomerações urbanas brasileiras, foram consideradas as seguintes dimensões sociais e espaciais: densidade, fragmentação, orientação e centralidade. Os resultados obtidos foram compatíveis com as evidências apontadas pela literatura internacional, expondo os novos desafios para planejamento urbano e ambiental.
\end{abstract}

Palavras-chave: Crescimento urbano. Planejamento urbano. Meio ambiente.

\section{Introdução}

Dois fatores devem ser considerados no processo de crescimento urbano: o populacional e o padrão de expansão física das ocupações urbanas. O primeiro representa um desafio em si mesmo quando exerce um importante peso na expansão da infraestrutura urbana. Já o padrão de ocupação pode e deve ser entendido como um fator essencial para que esse crescimento possa se dar com maior ou menor custo social, refletindo impactos sobre as formas de reprodução social e a sustentabilidade ambiental (UNFPA, 2007).

Segundo Angel (2006), há que se distinguir estes dois processos, pois é natural que o crescimento da população urbana leve a uma expansão das áreas urbanas para comportar esse contingente populacional dentro das cidades. Mas o que se desenha enquanto um desafio, no século 21 , não é apenas a pressão dos números, mas como as formas urbanas se moldam e são moldadas pelas tensões entre crescimento populacional e expansão urbana.

Resumindo, duas aglomerações urbanas podem apresentar taxas de crescimento populacional semelhantes no mesmo período, mas uma pode configurar uma forma urbana compacta, verticalizada e monocêntrica e outra poderá conformar o seu espaço urbano de modo disperso, horizontalizado e policêntrico, cada qual representando custos sociais e ambientais distintos. Com o surgimento do termo urban

\footnotetext{
* Este estudo foi desenvolvido no âmbito dos projetos: "Dinâmica intrametropolitana e vulnerabilidade sociodemográfica nas metrópoles do interior paulista", sob o financiamento da Fapesp e do CNPq; e "Desafios para a urbanização sustentável no espaço intrametropolitano de Campinas e Santos: mobilidade populacional, vulnerabilidade socioambiental e as evidências (locais, regionais e globais) das mudanças ambientais", sob o financiamento da Fapesp.

** Sociólogo e doutor em Demografia. Pesquisador colaborador do Departamento de Demografia (IFCH/Unicamp) e do Núcleo de Estudos de População (Nepo/Unicamp); bolsista de pós-doutorado da Fundação de Amparo à Pesquisa do Estado de São Paulo (Fapesp).
} 
sprawl, primeiramente nos Estados Unidos como uma designação pejorativa para expressar a expansão descontrolada das aglomerações urbanas em meados da década de 60 , sobretudo pela disseminação do padrão suburbano de urbanização (KIEFER, 2003), estudos passaram a procurar elementos que permitissem avaliar em que medida uma forma de ocupação do espaço poderia apresentar impactos sociais, econômicos e ambientais diferenciados. Embora a conceituação do termo urban sprawl ainda seja controversa, é grande o número de pesquisas que adotam distintos aportes metodológicos para apreender os impactos das diferentes formas de expansão urbana, inclusive em outras partes do mundo.

O objetivo deste trabalho é apresentar, a partir do resgate dessas abordagens internacionais, um aporte metodológico que permita analisar de modo comparativo as formas urbanas dentro do contexto das redes urbanas brasileiras sob a perspectiva das características formais da ocupação urbana. Não se trata de avaliar, em termos conceituais, se o que se denomina de urban sprawl, ${ }^{1}$ no caso norte-americano, pode ser aplicado no Brasil, mas sim trazer para a discussão sobre população, espaço e ambiente uma abordagem metodológica pouco enfatizada na literatura brasileira: a dimensão da dialética socioespacial com ênfase nos impactos do espaço sobre a sociedade.

Segundo Veiga (2000, p. 22), o paradigma da economia política foi a perspectiva dominante nas análises urbanas brasileiras e latino-americanas das últimas décadas. Neste contexto, pode-se dizer que os estudos urbanos brasileiros carecem de novas abordagens metodológicas que permitam avançar sobre questões contemporâneas. Por essa tradição, esbarram em duas premissas distintas e simultâneas: uma de ordem teórica; e outra metodológica.
A primeira dimensão, de natureza teórica, diz respeito à preconização da perspectiva histórica sobre a espacial, em uma dialética socioespacial incompleta na compreensão da problemática urbana. De certo modo, a conjuntura social, econômica e ideológica que perpassa as discussões teóricas acerca dos temas urbanos, na segunda metade do século 20 , acaba por consolidar paradigmas e modelos interpretativos que buscam, acima de tudo, elucidar as origens da desigualdade e da pobreza urbana no processo de desenvolvimento industrial tardio latino-americano. Segundo Faria (1991), parece ter havido um lapso de conceituação mais aprofundado no que se refere aos termos utilizados nas análises da sociedade urbana; assim, termos como urbano, cidade, espaço e até região metropolitana, entre outros, assumem sentidos e significados meramente convencionais sob uma base extensa e plural de temas e perspectivas teóricas.

Segundo Soja (1993), houve uma epistemologia essencialmente histórica que ainda hoje perpassa a consciência crítica da moderna teoria social. Assim, "o espaço ainda tende a ser tratado como fixo, morto e não dialético, e o tempo, como riqueza, a vida, a dialética e o contexto revelador da teorização social crítica" (SOJA, 1993). Dessa forma, a delimitação conceitual do campo de atuação das pesquisas urbanas se deu em torno dos impactos decorrentes do processo de urbanização e do agravamento dos problemas sociais, principalmente a partir da transferência de população de áreas tipicamente agrárias para as aglomerações urbanas. Parece ter havido, portanto, uma perspectiva na qual a associação entre processo de urbanização e a industrialização limitou, em parte, a compreensão dos aspectos espaciais da urbanização.

Para Vilmar Faria (1991), "a reflexão sobre a sociedade urbana no Brasil se funde e confunde com a reflexão sobre os

\footnotetext{
1 Ou dispersão urbana, tradução livre do termo em inglês utilizado para essa abordagem, urban sprawl. Embora a tradução literal do termo remeta a "espraiamento urbano", optou-se pelo termo dispersão. Outras referências, como Indovina (1990) e Scott et al. (2001), apontam para a análise deste processo a partir de outras abordagens, como cidade difusa e cidade-região.
} 
processos de mudança social que caracterizam a constituição de uma sociedade urbano-industrial". Pode-se considerar, então, que grande parte dos estudos urbanos brasileiros consolidou-se sob a égide do paradigma da produção social do espaço, em que espaço urbano é tratado como a expressão material do modo de produção capitalista. Entretanto, Villaça (1999) salienta que, apesar de muito se falar em produção do espaço, pouco se avançou sobre o consumo, a troca e a circulação desse "produto" social; e quase nada se disse a respeito dos efeitos do espaço sobre o social, pois, evidentemente, o espaço nunca adquiriu peso significativo nestes estudos para que pudesse ser tratado como uma variável relevante e eventualmente capaz de interferir nos processos sociais. É preciso, portanto, incorporar a dimensão espacial para a compreensão mais ampla da sociedade.

Assim, se o espaço é produzido socialmente, enquanto soma dos valores e signos da sociedade moderna, entendê-lo como parte das relações dialéticas espaço-sociedade só será possível se compreendermos as mudanças dos valores e re-significações que a sociedade contemporânea atravessa. Ou seja, muito mais do que entender as transformações da economia para entender as novas formas de organização do território, pode-se buscar identificar, nas formas espaciais, indicadores para compreender como mudam as formas de consumir a cidade, pois há um "deslocamento" das relações sociais de contextos locais de interação e uma conseqüente reestruturação dela através de extensões indefinidas de tempo-espaço (GIDDENS, 1991).

Para se aproximar de uma abordagem que traga novos elementos teóricos e metodológicos, o artigo está dividido em duas partes. A primeira coloca em discussão os aspectos metodológicos que podem ser considerados na construção de um indicador sintético para mensurar, de forma comparativa, as configurações formais das aglomerações urbanas brasileiras. Esta abordagem se deu, principalmente, com base na revisão da literatura internacional acerca do estudo do urban sprawl - característica marcante da urbanização norte- americana -, que, metodologicamente, pode ser importante para a compreensão da urbanização brasileira a partir de uma análise comparativa, privilegiando o espaço como categoria analítica. Posteriormente, são apresentados os principais resultados, validando o indicador em termos de seu potencial analítico e sua capacidade de relacionar indicadores socioespaciais e os impactos do espaço na dimensão social.

\section{Dimensões formais da expansão urbana}

Entre 1970 e 1990, a população da região de Los Angeles cresceu em torno de $45 \%$, mas, no mesmo período, sua área urbana ocupada aumentou em 300\% (MEADOWS, 1999); ou seja, houve uma redução significativa na densidade urbana dessa região, sobretudo pelo avanço das regiões periféricas em detrimento da importância desempenhada pelo centro urbano consolidado. Mesmo em cidades européias, tradicionalmente associadas a desenho urbano compacto (RICHARDSON; CHANG-HEE, 2004), há sinais de que a urbanização dispersa se encontra cada vez mais presente.

O crescimento das áreas urbanas segundo o padrão de expansão periférica não é novidade; mas, o que parece ser novo são as formas espaciais que as ocupações urbanas passam a assumir, principalmente a partir do final do século 20. Segundo Richardson e Chang-hee (2004, p. 1), parece haver uma convergência nos padrões de assentamento urbano encontrados nos Estados Unidos e na Europa Ocidental. Mas isso ocorre também em países em desenvolvimento? Em caso positivo, quais seriam as dimensões que evidenciam os padrões de ocupação na urbanização e, em termos práticos, como poderíamos medir as dimensões da forma urbana de modo comparativo no caso das aglomerações urbanas brasileiras?

A literatura internacional que estuda a dispersão urbana (ou urban sprawl) identifica alguns elementos constitutivos das áreas urbanas enquanto dimensões formais empiricamente observáveis nas regiões metropolitanas para dimensionar em que 
medida o processo pode ser percebido ao longo do país. A Figura 1 ilustra esquematicamente como a distribuição espacial da população no espaço intra-urbano pode assumir distintas expressões, apesar de apresentarem uma mesma densidade populacional.

Os modelos 1 e 2 apresentam uma distribuição espacial tipicamente monocêntrica, mas com diferentes distribuições espaciais,

FIGURA 1

Diagrama ilustrativo de distintas formas de ocupação urbana
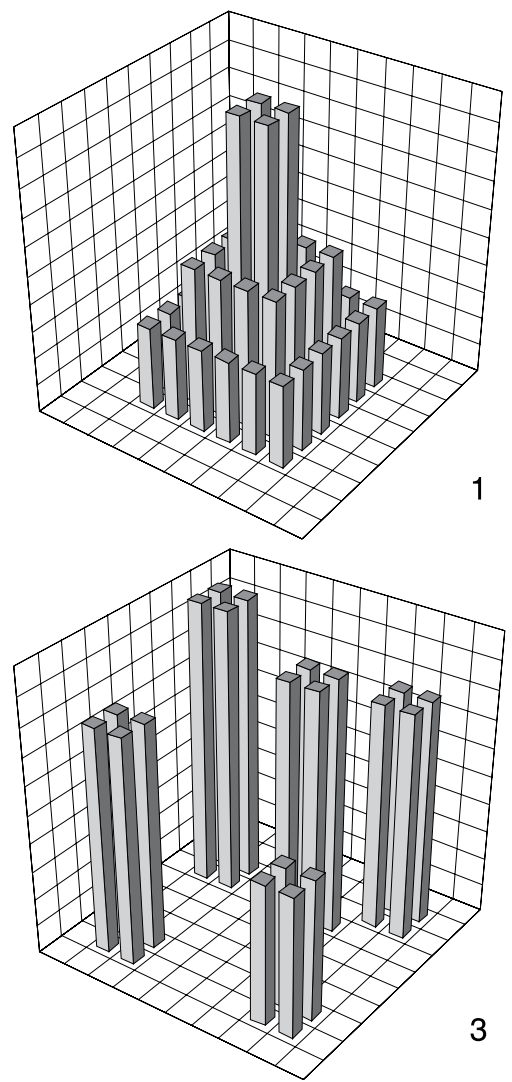

3

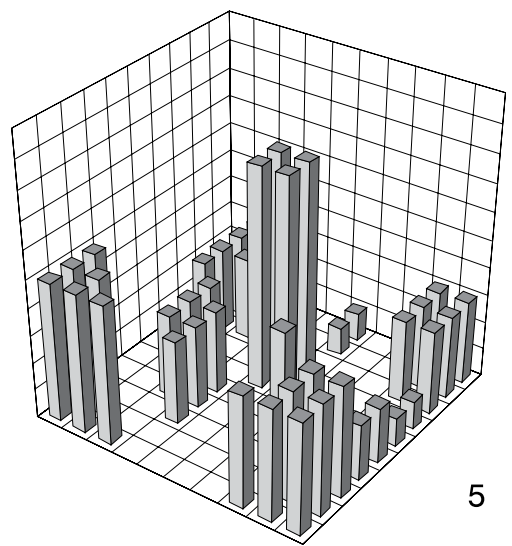

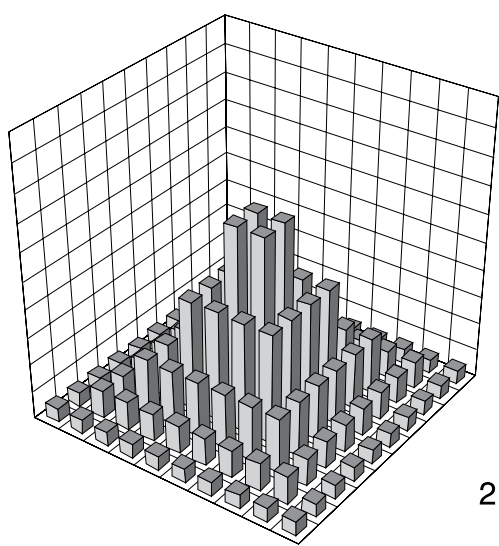

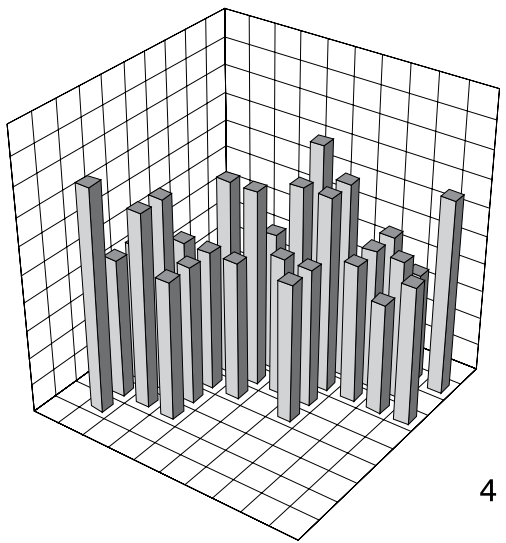

4

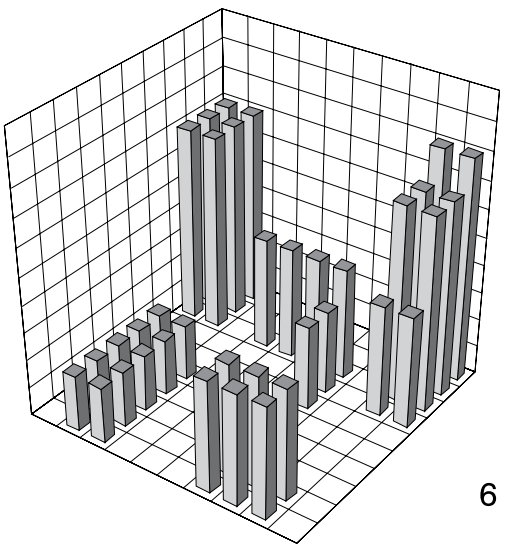


sendo a primeira mais compacta do que a segunda. $O$ modelo 3 é claramente mais fragmentado e, assim como o 2, poderia ser classificado como mais disperso do que o modelo 1. Os modelos 4, 5 e 6 parecem conter mais similaridades; entretanto, o modelo 4 possui uma continuidade da ocupação mais pronunciada do que os modelos 5 e 6.

Se esses modelos representassem áreas ou aglomerações urbanas, o que poderia ser dito a respeito? As pessoas que vivem em duas áreas distintas, como, por exemplo, nas aglomerações 1 e 5 , teriam atividades cotidianas similares? A hipótese é de que o espaço urbano - socialmente construído e reflexo de diversos interesses e ações sociais - reflete impactos diferenciados na vida urbana, de acordo com as suas características formais. Em relação aos impactos ambientais, as características da forma de expansão urbana parecem ser mais evidentes, dado que, intuitivamente, o diagrama 3 (mais disperso) pode apresentar menos áreas verdes contínuas, ${ }^{2}$ maior demanda por transporte automotivo, entre outras.

Claro que não é possível resumir a complexidade da urbanização em modelos esquemáticos simplificados e classificá-los a partir dessa categorização, mas é inquestionável que as aglomerações urbanas brasileiras assumem formas espaciais muito distintas. Em termos da percepção da pessoa que viaja de uma cidade para outra, não é raro ela dimensionar a cidade de destino em relação à de origem, classificando-a em termos de distâncias percorridas de um ponto a outro de atividade, de organização dos espaços, de congestionamentos, de dificuldades de acesso, entre outros.

Neste sentido, o objetivo desta seção é propor medidas que permitam classificar as aglomerações urbanas brasileiras em termos do que se poderia entender como dispersão urbana. Para tanto, estas dimensões foram aplicadas para 37 aglomerações urbanas, ${ }^{3}$ para construir um ranking da dispersão urbana.

Cabe esclarecer que, ao usar o termo "aglomeração urbana", não se está fazendo referência à figura institucional prevista constitucionalmente. Consideraram-se, para a delimitação destas unidades de análise, os critérios propostos pela pesquisa $\mathrm{Ca}$ racterísticas e tendências da rede urbana no Brasil (IPEA/IBGE/UNICAMP, 2000), na qual foram avaliadas as características de integração regional e dinâmica econômica, entre outras, para propor um conjunto de 49 aglomerados urbanos, entre os quais foram selecionados 37 onde, a partir das informações de mobilidade pendular do Censo Demográficos 2000, identificaram-se critérios mínimos de movimentos pendulares internos à própria aglomeração. ${ }^{4}$

Algumas das dimensões puderam ser observadas recorrentemente na literatura e se concentram, sobretudo, segundo as seguintes características: densidade, fragmentação, orientação e centralidade. Cada uma destas dimensões será explorada individualmente nos itens seguintes, justificando suas potencialidades na mensuração da forma urbana e sua aplicabilidade a partir dos dados disponíveis em âmbito nacional.

\footnotetext{
2 É importante mencionar que existe um debate a respeito da importância da manutenção de áreas verdes contínuas para que se viabilizem "corredores ecológicos" para a manutenção da biodiversidade, inclusive em áreas urbanas. No caso da dispersão urbana, embora seja possível perceber maior integração de áreas verdes dentro do tecido urbano (como no diagrama 3), essas áreas estão fragmentadas dentro do tecido urbano. Assim, embora realizem as demandas por "qualidade de vida" da população dos centros urbanos, com áreas verdes mais próximas à vida cotidiana das pessoas, essas extensões de áreas verdes se distribuem de maneira fragmentada no espaço urbano e não seriam suficientes para reproduzir a biodiversidade com a mesma potencialidade do que se estivessem dispostas de maneira contínua.

${ }^{3}$ As aglomerações urbanas selecionadas tiveram como base a publicação Caracterização e tendências da rede urbana brasileira (IPEA/IBGE/UNICAMP, 2000).

4 Foram selecionadas aquelas aglomerações nas quais predominavam movimentos pendulares intra-aglomerações e considerando apenas os municípios que possuíam integração regional com base nos movimentos pendulares dessas regiões. Foram consideradas, portanto, as aglomerações urbanas de São Paulo, Rio de Janeiro, Salvador, Belo Horizonte, Fortaleza, Brasília, Curitiba, Recife, Porto Alegre, Belém, Goiânia, Campinas, São Luis, Maceió, Natal, João Pessoa, São José dos Campos, Ribeirão Preto, Sorocaba, Aracaju, Londrina, Santos, Joinvile, São José do Rio Preto, Caxias do Sul, Jundiaí, Florianópolis, Maringá, Vitória, Volta Redonda, Blumenau, Ipatinga, Criciúma, Itajaí, Cabo Frio, Mogi-Mirim e Guaratinguetá. Mais detalhes sobre o critério de seleção pode ser obtido em Ojima (2007).
} 


\section{Densidade populacional urbana}

Entre os fatores que evidenciam a mudança no padrão de ocupação urbana, está o fato de que, recentemente, há um descompasso entre o crescimento da população urbana e a expansão das áreas urbanas. Segundo pesquisa publicada pelo Sierra Club (2003), o ritmo de crescimento das áreas urbanas, nos Estados Unidos, excede em pelo menos duas vezes aquele verificado para a população.

Neste aspecto, uma das formas de se mensurar este descompasso em áreas metropolitanas distintas seria a análise das densidades populacionais; assim, a densidade aparece como um dos indicadores mais usados para quantificar a dispersão urbana (GALSTER et al., 2001). Entretanto, o uso da densidade média considera todo o espaço da aglomeração urbana, inclusive o não dedicado a ocupações urbanas, levando a uma distorção do fenômeno.

Se forem utilizadas as áreas totais dos diagramas 1 e 2 da Figura 2 para calcular a densidade, o resultado seria a mesma densidade média, pois para ambas o volume hipotético da população é de 312 unidades distribuídas em uma mesma área. Entretanto, se considerada a área efetivamente urbanizada (as áreas em cinza do diagrama), a densidade populacional no diagrama 1 seria muito maior do que no 2 , embora o volume populacional continue sendo o mesmo.
Neste sentido, o cálculo da densidade populacional urbana é mais relevante para quantificar a dispersão urbana.

Do ponto de vista prático, a mensuração da área considerada urbana é um desafio em si mesmo. Com a relativa popularização das imagens de satélite nos estudos urbanos, vários trabalhos passaram a utilizar técnicas de sensoriamento remoto, de modo a estimar a área urbanizada em diversas localidades. Particularmente para o estudo dos processos de expansão urbana, essa prática tem sido recorrente.

Os trabalhos de Galster et al. (2001), Batty, Xie e Sun (1999), Chin (2002), Torrens e Alberti (2000), Cutsinger et al. (2005), Roca, Burns e Carreras (2004), Angel Sheppard e Civco (2005), entre outros, utilizam imagens de satélite para avaliar a expansão urbana em diversas partes do mundo. Angel, Sheppard e Civco (2005) apresentam um dos mais abrangentes estudos considerando um conjunto de aproximadamente quatro mil cidades com população superior a 100 mil habitantes ao redor do globo. Segundo este trabalho, as densidades das cidades de países em desenvolvimento tendem a ser maiores do que nos países desenvolvidos, mas, em ambos os grupos, a tendência ao longo do tempo tem sido de redução.

O Global Rural-Urban Mapping Project (GRUMP), desenvolvido no âmbito do Center for International Earth Science

FIGURA 2

Diagrama ilustrativo de distintas densidades urbanas
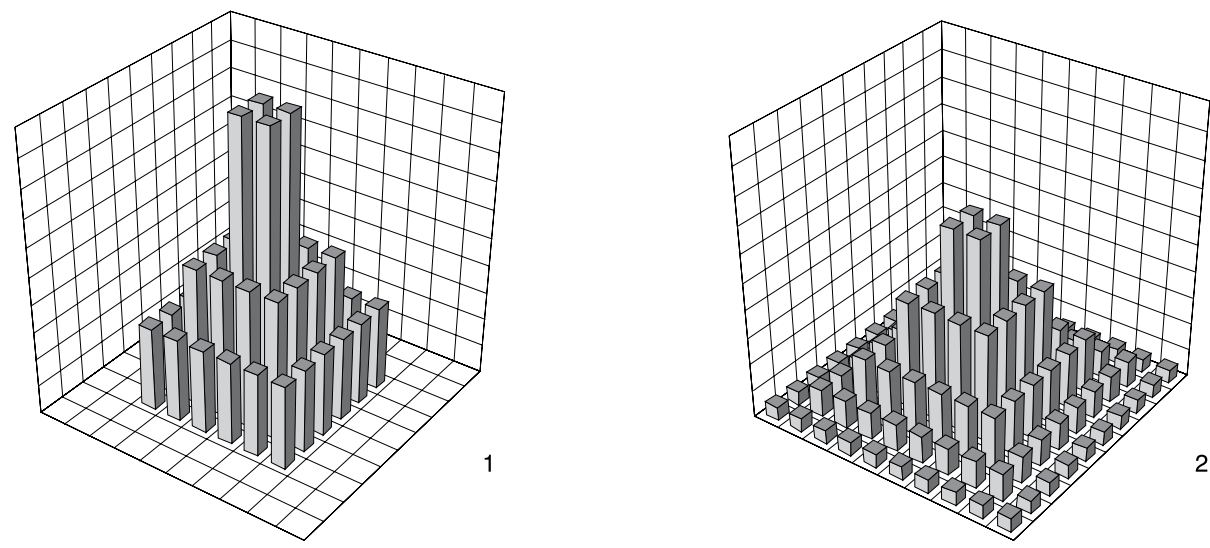
Information Network (CIESIN), Columbia University, utiliza imagens de satélite e a leitura dos dados dos pontos de luz emitidos pelas aglomerações urbanas para realizar uma estimativa das áreas urbanizadas. Entretanto, o uso sistemático desses instrumentos ainda possui algumas limitações operacionais, tais como o elevado custo para aquisição das imagens e posterior processamento e análise, sobretudo quando se consideram recortes espaciais mais detalhados e não usuais, como é o caso do estudo de aglomerações urbanas que não fazem parte de regiões metropolitanas institucionalizadas, ou ainda quando o objetivo é realizar uma investigação que inclua um conjunto maior de áreas de estudo.

Outra questão que permeia a utilização das imagens de satélite refere-se aos problemas de classificação das imagens, pois, tratando-se de um processo automatizado, demanda a realização de estudos empíricos para confirmar a classificação das imagens. Como se sabe, o conceito de "urbano" não é totalmente consensual e depende, em certo grau, de uma classificação subjetiva. ${ }^{5}$ A utilização das imagens de satélite não elimina esta subjetividade, pois, apesar de sua evidência empírica, ainda se trata de um processo de classificação que depende da qualidade e resolução da imagem e do grau de detalhamento que ela consegue captar.

Neste sentido, a informação contida nos Censos Demográficos, embora possua suas limitações em termos da classificação do que é rural ou urbano, apresenta algumas vantagens, tais como uniformidade, acessibilidade e abrangência da informação. Ou seja, é possível obter com facilidade os dados de forma homogênea para todo o país.

Garcia e Matos (2005) utilizaram, em pesquisa recente, informações disponibilizadas na forma de Malha Digital de Setores Censitários Rurais e destacam a subutilização dessa base de dados. Esta informação está disponível na Internet, no sítio eletrônico do Instituto Brasileiro de Geografia e Estatística (IBGE), ${ }^{6}$ sem custo, e inclui a classificação dos setores censitários urbanos e rurais para todos os municípios do país.

Como forma de oferecer maior detalhamento às categorias rural e urbano, o Censo Demográfico ainda subdivide as áreas urbanas e rurais em oito subcategorias, sendo três delas relativas ao urbano e outras cinco referentes ao rural. $^{7}$ Para fins analíticos, utilizamos esta classificação, considerando as quatro primeiras subcategorias como representativas das áreas urbanas, pois, apesar da categoria quatro ser classificada como rural, está relacionada ao processo de expansão urbana sobre áreas classificadas oficialmente como rurais.

O total das áreas urbanas no Brasil, segundo esse critério, é de cerca de $95 \mathrm{mil}$ quilômetros quadrados, o que representa apenas $1,12 \%$ do território brasileiro que comportava cerca de 140 milhões de pessoas, em 2000 , ou seja, $81,8 \%$ do total da população. A partir desses dados, é possível verificar com maiores detalhes a informação de densidade populacional, que, em termos da área total, é de cerca de 20 habitantes por quilômetro quadrado, mas que, se considerada apenas a densidade relativa à população que vive em áreas urbanas, passa

\footnotetext{
5 Os critérios para a delimitação do "urbano”, na maioria das vezes, não são uniformes. Entre os países, podem ser desde aqueles em países como a Albânia, que consideram urbanas as localidades com pelo menos 400 habitantes, ou como na Áustria, onde este limite inferior é de 5 mil habitantes. Na Bulgária, são consideradas urbanas as áreas constituídas legalmente, independentemente de tamanho populacional; em Israel são os centros predominantemente não-agrícolas; na Suécia são consideradas as áreas onde não haja distância superior a 200 metros entre as residências; no Japão são consideradas as municipalidades com mais de 50 mil habitantes, desde que possuam pelo menos $60 \%$ das residências em áreas antropizadas e pelo menos $60 \%$ dos habitantes empregados em atividades industriais, comerciais ou outras tipicamente urbanas. No caso brasileiro, por resolução legal, toda sede de município ou distrito é considerada área urbana, sendo seu perímetro definido por legislação municipal. Ou seja, a classificação do que é urbano no Brasil é atribuído aos municípios, independentemente de qualquer critério conceitual ou analítico.

6 <http://www.ibge.gov.br/home/geociencias/default_prod.shtm\#TOPO>; último acesso em 06/10/2007.

7 1. Área urbanizada de vila ou cidade; 2 . Área não urbanizada de vila ou cidade; 3 . Área urbana isolada; 4 . Rural - extensão urbana; 5 . Rural - povoado; 6 . Rural - núcleo; 7. Rural - outros aglomerados; 8 . Rural - exclusive os aglomerados rurais.
} 
a ser de 1.453 mil habitantes por quilômetro quadrado.

As 37 aglomerações urbanas representam cerca de um terço do total da área urbana brasileira (30,5 mil quilômetros qua- drados) e abrigam 71,6 milhões de pessoas. Assim, a densidade populacional urbana nessas aglomerações é, em média, de 2.353 habitantes por quilômetro quadrado. A área urbana $(A U)$ de Maringá é a que possui

TABELA 1

População total, domicílios, área urbana, densidade populacional e densidade domiciliar Aglomerações brasileiras - $\mathbf{2 0 0 0}$

\begin{tabular}{|c|c|c|c|c|c|c|}
\hline $\begin{array}{c}\text { Aglomerações } \\
\text { urbanas }\end{array}$ & População & Domicílios & $\begin{array}{l}\text { Área urbana } \\
\left(\mathrm{em} \mathrm{km} \mathbf{k m}^{2}\right)\end{array}$ & $\begin{array}{c}\text { Densidade } \\
\text { populacional } \\
\left(\text { hab. } / \mathbf{k m}^{2}\right)\end{array}$ & $\begin{array}{l}\text { Densidade } \\
\text { domicíliar } \\
\left.\text { (dom. } / \mathbf{k m}^{2}\right)\end{array}$ & $\begin{array}{c}\text { Número } \\
\text { médio de } \\
\text { habitantes } \\
\text { por domicílio }\end{array}$ \\
\hline São Paulo & 17.596 .957 & 5.000 .541 & $4.033,50$ & $4.362,7$ & $1.239,8$ & 3,5 \\
\hline Rio de Janeiro & 10.870 .155 & 3.295 .702 & $5.128,16$ & $2.119,7$ & 642,7 & 3,3 \\
\hline Salvador & 2.959 .434 & 791.007 & 696,14 & $4.251,2$ & $1.136,3$ & 3,7 \\
\hline Belo Horizonte & 4.210 .662 & 1.151 .418 & $1.666,49$ & $2.526,7$ & 690,9 & 3,7 \\
\hline Fortaleza & 2.821 .761 & 692.926 & $1.278,83$ & $2.206,5$ & 541,8 & 4,1 \\
\hline Brasília & 2.623 .303 & 701.028 & $2.083,55$ & $1.259,1$ & 336,5 & 3,7 \\
\hline Curitiba & 2.502 .129 & 728.859 & $1.184,91$ & $2.111,7$ & 615,1 & 3,4 \\
\hline Recife & 3.238 .736 & 849.458 & 973,43 & $3.327,1$ & 872,6 & 3,8 \\
\hline Porto Alegre & 3.436 .431 & 1.065 .320 & $1.566,11$ & $2.194,2$ & 680,2 & 3,2 \\
\hline Belém & 1.965 .794 & 412.634 & 404,53 & $4.859,5$ & $1.020,0$ & 4,8 \\
\hline Goiânia & 1.560 .625 & 447.284 & 724,37 & $2.154,5$ & 617,5 & 3,5 \\
\hline Campinas & 2.119 .322 & 610.616 & $1.167,06$ & $1.815,9$ & 523,2 & 3,5 \\
\hline São Luís & 945.280 & 221.409 & 332,56 & $2.842,4$ & 665,8 & 4,3 \\
\hline Maceió & 865.717 & 220.414 & 244,90 & $3.535,0$ & 900,0 & 3,9 \\
\hline Natal & 961.638 & 241.998 & 248,07 & $3.876,5$ & 975,5 & 4,0 \\
\hline João Pessoa & 828.712 & 212.388 & 315,22 & $2.629,0$ & 673,8 & 3,9 \\
\hline São José dos Campos & S 1.172 .423 & 319.772 & 869,79 & $1.347,9$ & 367,6 & 3,7 \\
\hline Ribeirão Preto & 603.452 & 173.083 & 309,48 & $1.949,9$ & 559,3 & 3,5 \\
\hline Sorocaba & 873.329 & 242.659 & 505,68 & $1.727,0$ & 479,9 & 3,6 \\
\hline Aracaju & 703.983 & 178.052 & 711,11 & 990,0 & 250,4 & 4,0 \\
\hline Londrina & 564.768 & 162.867 & 311,64 & $1.812,2$ & 522,6 & 3,5 \\
\hline Santos & 1.350 .446 & 395.757 & 716,33 & $1.885,2$ & 552,5 & 3,4 \\
\hline Joinvile & 566.106 & 160.270 & 606,87 & 932,8 & 264,1 & 3,5 \\
\hline São José do Rio Preto & 395.379 & 120.894 & 121,81 & $3.245,9$ & 992,5 & 3,3 \\
\hline Caxias do Sul & 518.069 & 158.949 & 271,36 & $1.909,2$ & 585,7 & 3,3 \\
\hline Jundiaí & 496.413 & 140.029 & 275,01 & $1.805,1$ & 509,2 & 3,5 \\
\hline Florianópolis & 698.447 & 207.661 & 647,42 & $1.078,8$ & 320,8 & 3,4 \\
\hline Maringá & 399.356 & 116.631 & 47,82 & $8.351,2$ & $2.439,0$ & 3,4 \\
\hline Vitória & 1.327.342 & 373.646 & 845,91 & $1.569,1$ & 441,7 & 3,6 \\
\hline Volta Redonda & 530.317 & 153.483 & 313,64 & $1.690,8$ & 489,4 & 3,5 \\
\hline Blumenau & 380.273 & 112.126 & 512,30 & 742,3 & 218,9 & 3,4 \\
\hline Ipatinga & 341.608 & 90.418 & 196,05 & $1.742,5$ & 461,2 & 3,8 \\
\hline Criciúma & 238.867 & 67.556 & 275,80 & 866,1 & 244,9 & 3,5 \\
\hline Itajaí & 326.236 & 95.286 & 287,29 & $1.135,6$ & 331,7 & 3,4 \\
\hline Cabo Frio & 204.939 & 59.885 & 346,57 & 591,3 & 172,8 & 3,4 \\
\hline Mogi-Mirim & 196.551 & 55.382 & 92,02 & $2.136,0$ & 601,8 & 3,5 \\
\hline Guaratingueta & 213.180 & 58.742 & 114,15 & $1.867,5$ & 514,6 & 3,6 \\
\hline Total & 71.608 .152 & 20.086 .149 & $30.425,80$ & $2.353,5$ & 660,2 & 3,6 \\
\hline
\end{tabular}

Fonte: IBGE. Censo Demográfico 2000 (microdados da amostra) e Malha Digital dos Setores Censitários Rurais 2000. 
a maior densidade, com cerca de 8,3 mil hab. $/ \mathrm{km}^{2}$, e a de Cabo Frio detém a menor, com 591 hab. $/ \mathrm{km}^{2}$. Assim, sob uma análise comparativa das aglomerações urbanas, existem situações muito distintas em termos da densidade urbana. A AU de São Paulo, apesar de possuir a segunda maior extensão urbana $(4,2 \%$ do total brasileiro), registra uma das densidades populacionais urbanas mais altas $\left(4,3\right.$ mil hab. $\left./ \mathrm{km}^{2}\right)$.

Mas, embora as densidades sejam importantes para identificar o padrão de expansão urbana e, conseqüentemente, a dispersão urbana, a densidade de domicílios remete mais diretamente à medida da distribuição da população dentro do espaço de uma aglomeração urbana. O total de domicílios nas aglomerações é de cerca de 20 milhões, o que corresponde a uma densidade de 660 domicílios por quilômetro quadrado.

A Tabela 1 apresenta as densidades populacionais e domiciliares nas áreas urbanas para as aglomerações selecionadas e permite verificar as distintas condições em termos da densidade urbana. Com base nestas informações, observa-se que a AU de Blumenau é a que possui um grau de dispersão urbana mais evidente, pois a distribuição dos domicílios urbanos se dá sob uma densidade de 218 domicílios por quilômetro quadrado, a mais baixa entre as trinta e sete aglomerações. A AU de Maringá detém a maior densidade de domicílios urbanos e, a partir desse critério, poderia ser classificada como a aglomeração urbana mais compacta.

\section{Fragmentação}

Entretanto, a densidade urbana não é necessariamente um indicador que garante a existência de uma urbanização mais dispersa nas aglomerações, sendo que o padrão de ocupação do espaço urbano dentro da aglomeração também contribui para que a urbanização seja mais ou menos dispersa. Isso pode ocorrer em casos como o ilustrado pela Figura 3, em que as duas áreas urbanas hipotéticas possuem a mesma densidade urbana, embora apresentem padrões de distribuição da área urbana muito distintos.

No diagrama 1, tem-se uma forma de ocupação monocêntrica, enquanto no 2 existem diversos núcleos separados espacialmente. É o caso do que a literatura sobre o urban sprawl aponta como leapfrog development, ou urbanização em saltos, que se caracteriza pela fragmentação dos espaços urbanos e está associada à separação física dos núcleos de desenvolvimento urbano.

Essa urbanização em saltos pode ser entendida como parte de um processo de desconexão dos espaços de vida cotidianos dentro das aglomerações, claramente as-

FIGURA 3

Diagrama ilustrativo de distintas formas de fragmentação da área urbana
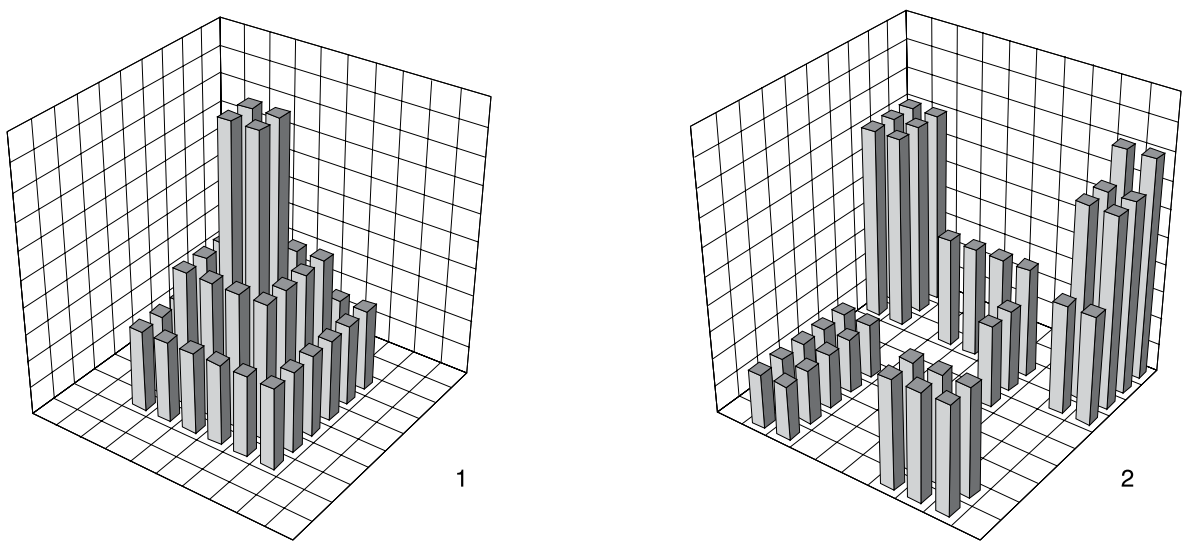
sociado às mudanças nos deslocamentos espaciais da população, uma vez que a continuidade da mancha urbana não é mais necessária para que os contextos urbanos sejam integrados. Essa forma de desenvolvimento urbano é, depois da densidade urbana, o fator mais característico da dispersão urbana, pois adiciona uma evidência espacial ao padrão de distribuição da população dentro dos contextos urbanos.

Em termos operacionais, a fragmentação dos espaços urbanos pode ser apreendida de distintas formas e, como pode ser observado de modo intuitivo pela Figura 3, a distância que os espaços urbanizados possuem entre si caracteriza a maior ou menor dispersão de uma região. Ou seja, se duas regiões possuem uma mesma população distribuída em uma área urbana equivalente, elas terão densidades urbanas próximas, mas uma pode assumir uma forma compacta em círculos concêntricos, enquanto outra pode ter uma forma policêntrica, com ramos urbanos indo para distintas direções.

Essa é uma importante dimensão da expansão urbana, pois a urbanização em saltos pode comprometer usos agrícolas das áreas periféricas, ou ainda demandar a expansão da rede de infra-estrutura de serviços - como abastecimento de água e esgoto - para além do minimamente necessário (ANGEL; SHEPPARD; CIVCO, 2005).

A questão ambiental surge aqui como um importante condicionante para esta dimensão da dispersão urbana, pois tanto suas causas como seus efeitos estão relacionados. Por um lado, tem-se a crescente demanda por uma vivência cotidiana próxima aos artefatos ambientais, ${ }^{8}$ mas, por outro, à medida que a urbanização avança em direção a eles, compromete-se a capacidade de ofertar tais amenidades. Assim, a tendência é de se criarem espaços urbanos cada vez mais desconectados uns dos outros, sendo que os espaços não-urbanizados que se colocam entre eles tornam-se pouco utilizados em termos ambientais, agrícolas ou mesmo de atividades urbanas.

Para medir essa dimensão da urbanização, utilizou-se o Índice de Vizinhança Próxima, ${ }^{9}$ a partir do software ArcGis (versão 9.0). Para calcular essa medida de dispersão, primeiramente foram agrupados os setores censitários urbanos conurbados de uma aglomeração urbana, para se criar um único polígono para cada área urbanizada, evidenciando as áreas urbanas sem fronteiras adjacentes. A Figura 4 ilustra o procedimento realizado.

Assim, cada conjunto de setores censitários urbanos de uma aglomeração foi agregado como um único polígono, mesmo quando sua área era dividida por limites municipais. Como pode ser observado na Figura 5, após o cálculo dos pontos centrais de cada um destes polígonos (centróides), calculou-se a distância entre cada um dos centróides e o seu vizinho mais próximo (Di).

A razão entre a média dessas distâncias (Di) e a média das distâncias em uma área hipotética com distribuição aleatória é um indicador que permite medir o grau de dispersão das áreas urbanizadas em cada uma das aglomerações urbanas. Esse indicador foi posteriormente ajustado para que seus valores variassem entre zero e um. Dessa forma, valores próximos de zero representam padrões mais compactos, enquanto aqueles próximos de um significam padrões mais dispersos. O mesmo procedimento foi, portanto, realizado para cada uma das 37 aglomerações urbanas.

Juntamente com essa medida, foi utilizada a razão entre a área não-urbana e a área urbana de cada uma das aglomerações, como forma de mensurar a existência de espaços não-urbanizados. Assim, a média aritmética destes dois indicadores resultou em uma medida sintética (indicador de fragmentação), combinando uma medida de dispersão e os espaços não-urbanizados para todas as aglomerações apresentadas na Tabela 2.

\footnotetext{
8 Áreas verdes, parques, lagos, praças, etc.

9 Tradução livre do termo em inglês: Average Nearest Neighbor Index
} 
FIGURA 4

Agrupamento dos setores censitários conurbados

Aglomeração urbana de Brasília - 2000
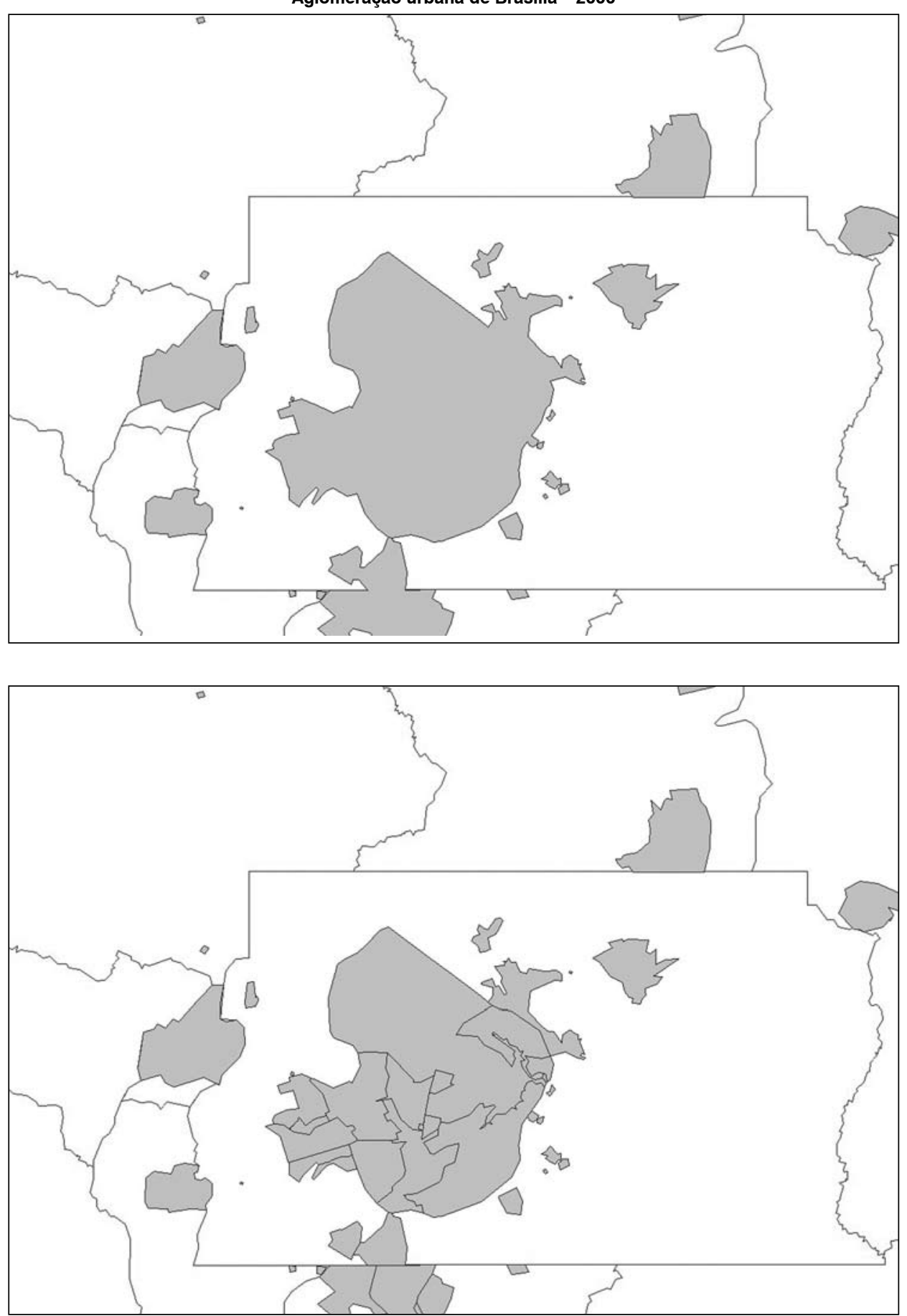

Fonte: IBGE. Malha Digital dos Setores Censitários Rurais 2000. 
FIGURA 5

Diagrama ilustrativo da metodologia de cálculo do indicador de fragmentação

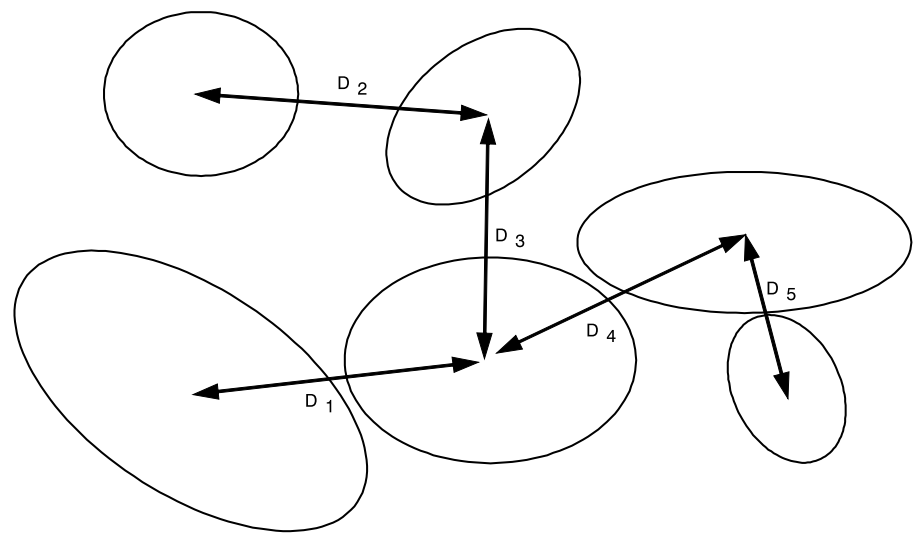

TABELA 2

Indicadores de vizinhança, de área não-urbanizada e de fragmentação Aglomerações urbanas brasileiras - $\mathbf{2 0 0 0}$

\begin{tabular}{|c|c|c|c|}
\hline Aglomerações urbanas & $\begin{array}{c}\text { Indicador de } \\
\text { vizinhança }\end{array}$ & $\begin{array}{l}\text { Indicador de área } \\
\text { não-urbanizada }\end{array}$ & $\begin{array}{l}\text { Indicador de } \\
\text { fragmentação }\end{array}$ \\
\hline São Paulo & 0,507474 & 0,596288 & 0,551881 \\
\hline Rio de Janeiro & 0,510043 & 0,561902 & 0,535972 \\
\hline Salvador & 0,506744 & 0,867612 & 0,687178 \\
\hline Belo Horizonte & 0,509927 & 0,799578 & 0,654753 \\
\hline Fortaleza & 0,508427 & 0,732650 & 0,620538 \\
\hline Brasília & 0,521121 & 0,999861 & 0,760491 \\
\hline Curitiba & 0,513419 & 0,993102 & 0,753261 \\
\hline Recife & 0,507797 & 0,704222 & 0,606010 \\
\hline Porto Alegre & 0,511222 & 0,859887 & 0,685555 \\
\hline Belém & 0,506698 & 0,878143 & 0,692421 \\
\hline Goiânia & 0,506272 & 0,749456 & 0,627864 \\
\hline Campinas & 0,504337 & 0,670152 & 0,587244 \\
\hline São Luís & 0,502090 & 0,845094 & 0,673592 \\
\hline Maceió & 0,502942 & 0,824971 & 0,663956 \\
\hline Natal & 0,504136 & 0,987652 & 0,745894 \\
\hline João Pessoa & 0,504052 & 0,775588 & 0,639820 \\
\hline São José dos Campos & 0,511492 & 0,841248 & 0,676370 \\
\hline Ribeirão Preto & 0,509455 & 0,902392 & 0,705924 \\
\hline Sorocaba & 0,506870 & 0,834627 & 0,670749 \\
\hline Aracaju & 0,509277 & 0,575437 & 0,542357 \\
\hline Londrina & 0,509281 & 0,992914 & 0,751097 \\
\hline Santos & 0,510989 & 0,641895 & 0,576442 \\
\hline Joinvile & 0,507831 & 0,847868 & 0,677849 \\
\hline São José do Rio Preto & 0,506213 & 0,965161 & 0,735687 \\
\hline Caxias do Sul & 0,509768 & 0,999941 & 0,754854 \\
\hline Jundiaí & 0,503368 & 0,738709 & 0,621039 \\
\hline Florianópolis & 0,512588 & 0,969475 & 0,741031 \\
\hline Maringá & 0,508136 & 1,000000 & 0,754068 \\
\hline Vitória & 0,506384 & 0,639759 & 0,573072 \\
\hline Volta Redonda & 0,506874 & 0,953118 & 0,729996 \\
\hline Blumenau & 0,509180 & 0,904173 & 0,706676 \\
\hline Ipatinga & 0,506088 & 0,913666 & 0,709877 \\
\hline Criciúma & 0,504895 & 0,761600 & 0,633247 \\
\hline Itajaí & 0,510802 & 0,729249 & 0,620026 \\
\hline Cabo Frio & 0,505387 & 0,690380 & 0,597883 \\
\hline Mogi-Mirim & 0,505431 & 0,999999 & 0,752715 \\
\hline Guaratingueta & 0,507099 & 0,999998 & 0,753548 \\
\hline
\end{tabular}

Fonte: Elaboração própria. 
No indicador de fragmentação (IF), os valores mais baixos representam padrões menos fragmentados. As aglomerações com maior fragmentação são as de Brasília, Caxias do Sul e Maringá, enquanto as que possuem os padrões mais compactos correspondem a Rio de Janeiro, São Paulo e Aracaju, com destaque para as duas primeiras, pois, apesar de terem as maiores áreas urbanizadas (as duas representam cerca de $30 \%$ do total das 37 aglomerações urbanas), possuem grandes extensões de áreas urbanas conurbadas e, proporcionalmente, uma pequena área não-urbanizada. Ainda vale ressaltar que, neste indicador, a escala territorial da aglomeração urbana assume papel importante, pois, como o indicador considera a distância média entre as áreas urbanizadas, regiões onde há mais áreas classificadas como não-urbanas entre as áreas urbanizadas também serão aquelas mais dispersas. No caso da $\mathrm{AU}$ de São Paulo, por exemplo, a despeito de sua expressiva extensão territorial, a maior parte dessa área é classificada como urbana e, portanto, a conurbação é maior.

\section{Orientação/linearidade}

A orientação em que se dá a urbanização também assume papel importante no processo de expansão urbana e no conseqüente menor ou maior grau de dispersão. Algumas aglomerações podem se desenvolver condicionadas por constrangimentos físicos, como serras, rios, mar ou outras barreiras naturais, além de terem uma estreita relação com outros elementos, como rodovias, ferrovias, pólos econômicos regionais, etc.

Sob tais condições, a expansão urbana ocorre de forma diferenciada, constituindose, conseqüentemente, em fator que deve ser levado em conta quando se analisam as formas de ocupação do espaço. Uma aglomeração urbana que se desenvolve a partir de círculos concêntricos tem, potencialmente, maior capacidade de otimizar e distribuir sua infra-estrutura de serviços em comparação àquela que acompanha o traçado de uma rodovia e, por isso, tende a se expandir em apenas um sentido.

Assim, é importante diferenciar as aglomerações urbanas em termos da orientação dessa expansão, ou seja, se a forma é mais circular ou mais elipsoidal. Apoiando-se novamente nos diagramas de aglomerações hipotéticas, podem ser observadas duas áreas com a mesma densidade e pouca fragmentação das áreas urbanas (Figura 6). Entretanto, o padrão de desenvolvimento urbano em linha tende a caracterizar uma maior dispersão urbana, como pode-se perceber intuitivamente a partir da observação dos diagramas 1 e 2 .

FIGURA 6

Diagrama ilustrativo de distintas formas de orientação da área urbana
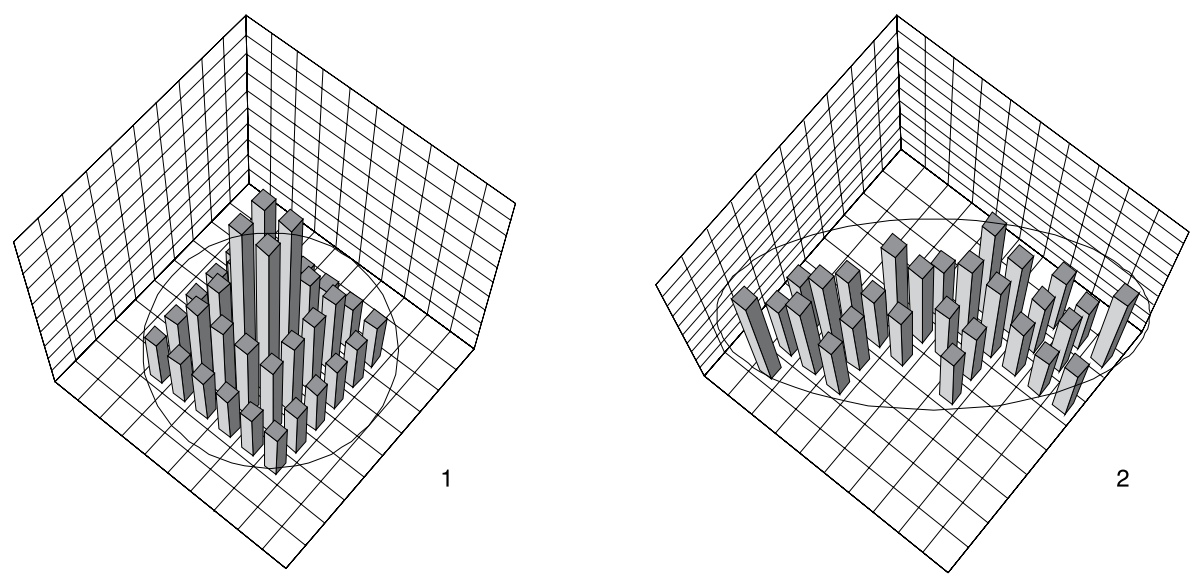
A partir da ferramenta de Distribuição Direcional, disponível no software ArcGis (versão 9.0), é possível medir se uma distribuição de polígonos segue uma determinada tendência direcional. Assim, após a identificação dos centróides dos polígonos dos setores censitários urbanos (agregados como no item anterior), gera-se um polígono em formato elíptico, em que seus eixos são obtidos pelo desvio-padrão dos centróides dos polígonos em relação ao eixo de rotação.

A diferença entre os eixos permite comparar as aglomerações em termos da orientação do desenvolvimento urbano. Nos diagramas 1 e 2 da Figura 6, a diferença entre os eixos indica o grau de "achatamento" da elipse. Assim, quando a diferença entre os eixos está perto de zero, como no diagrama 1, a tendência é de que a elipse seja mais próxima de um círculo. Em termos da análise da dispersão, considera-se que formas mais circulares tendem a ser mais compactas e, portanto, quanto maior for a diferença entre os eixos, mais dispersa será a aglomeração.

Assim, elaborou-se o indicador de linearidade, que mede o grau em que as áreas urbanizadas se distribuem e se ajustam a um formato mais circular ou elíptico. Enfim, como verifica-se na Figura 7, a diferença entre D1 e D2 é maior do que aquela entre D3 e D4 e, portanto, a tendência de linearidade é maior no primeiro caso.

Com os dados padronizados, variando de zero a um, aqueles próximos de zero são os mais circulares, enquanto os que se aproximam de um tendem a apresentar um padrão de urbanização em linha. Assim, as AU de Guaratinguetá, São Luís e Maceió são as que possuem as formas mais circulares, enquanto Rio de Janeiro, Santos e Blumenau têm um padrão mais elíptico. A Tabela 3 sintetiza as informações obtidas por esse procedimento e apresenta o indicador de linearidade ajustado.

\section{Centralidade}

Apesar de todas as dimensões consideradas aqui, é importante lembrar que, se não houver integração entre as áreas urbanizadas, pouco importa a forma que elas assumem, pois uma área muito dispersa em termos espaciais, mas onde o fluxo de movimentos pendulares ${ }^{10}$ é muito

FIGURA 7

Diagrama ilustrativo da metodologia de cálculo do indicador de orientação

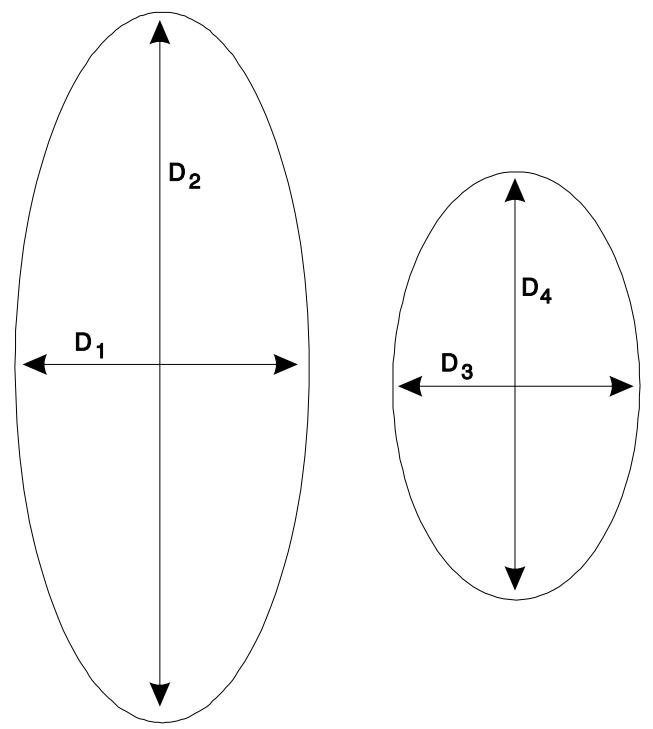

10 Obtida a partir da informação censitária de "município de trabalho e/ou estudo". 
TABELA 3

Eixos das elipses formadas pela ferramenta de distribuição direcional, diferença entre os eixos e indicador de linearidade

Aglomerações urbanas brasileiras $\mathbf{- 2 0 0 0}$

\begin{tabular}{|c|c|c|c|c|}
\hline Aglomerações urbanas & Eixo 1 & Eixo 2 & $\begin{array}{l}\text { Diferença entre } \\
\text { os eixos } 1 \text { e } 2\end{array}$ & $\begin{array}{l}\text { Indicador de } \\
\text { linearidade }\end{array}$ \\
\hline São Paulo & 0,441176 & 0,194153 & 0,247023 & 0,597555 \\
\hline Rio de Janeiro & 0,199811 & 0,897000 & 0,697189 & 0,757158 \\
\hline Salvador & 0,231182 & 0,134745 & 0,096437 & 0,538413 \\
\hline Belo Horizonte & 0,368077 & 0,459865 & 0,091788 & 0,536567 \\
\hline Fortaleza & 0,324692 & 0,228447 & 0,096245 & 0,538337 \\
\hline Brasília & 0,549457 & 0,754262 & 0,204805 & 0,581138 \\
\hline Curitiba & 0,381371 & 0,495693 & 0,114322 & 0,545509 \\
\hline Recife & 0,186138 & 0,385728 & 0,199590 & 0,579099 \\
\hline Porto Alegre & 0,373645 & 0,621580 & 0,247935 & 0,597908 \\
\hline Belém & 0,213778 & 0,110328 & 0,103450 & 0,541197 \\
\hline Goiânia & 0,255034 & 0,101435 & 0,153599 & 0,561037 \\
\hline Campinas & 0,321116 & 0,236737 & 0,084379 & 0,533622 \\
\hline São Luís & 0,085513 & 0,049549 & 0,035964 & 0,514344 \\
\hline Maceió & 0,106719 & 0,064356 & 0,042363 & 0,516895 \\
\hline Natal & 0,218222 & 0,097758 & 0,120464 & 0,547942 \\
\hline João Pessoa & 0,031081 & 0,133998 & 0,102917 & 0,540986 \\
\hline São José dos Campos & 0,204088 & 0,470597 & 0,266509 & 0,605076 \\
\hline Ribeirão Preto & 0,400174 & 0,139164 & 0,261010 & 0,602958 \\
\hline Sorocaba & 0,241025 & 0,195505 & 0,045520 & 0,518154 \\
\hline Aracaju & 0,101968 & 0,196912 & 0,094944 & 0,537820 \\
\hline Londrina & 0,213863 & 0,353992 & 0,140129 & 0,555721 \\
\hline Santos & 0,084895 & 0,426765 & 0,341870 & 0,633776 \\
\hline Joinvile & 0,263922 & 0,175317 & 0,088605 & 0,535302 \\
\hline São José do Rio Preto & 0,096826 & 0,202400 & 0,105574 & 0,542040 \\
\hline Caxias do Sul & 0,184828 & 0,445323 & 0,260495 & 0,602759 \\
\hline Jundiaí & 0,243963 & 0,103869 & 0,140094 & 0,555707 \\
\hline Florianópolis & 0,531899 & 0,316013 & 0,215886 & 0,585462 \\
\hline Maringá & 0,150571 & 0,237719 & 0,087148 & 0,534723 \\
\hline Vitória & 0,128774 & 0,357987 & 0,229213 & 0,590648 \\
\hline Volta Redonda & 0,324912 & 0,195729 & 0,129183 & 0,551394 \\
\hline Blumenau & 0,512855 & 0,197006 & 0,315849 & 0,623941 \\
\hline Ipatinga & 0,100394 & 0,205147 & 0,104753 & 0,541714 \\
\hline Criciúma & 0,137581 & 0,195778 & 0,058197 & 0,523204 \\
\hline Itajaí & 0,217323 & 0,034300 & 0,183023 & 0,572610 \\
\hline Cabo Frio & 0,103695 & 0,184237 & 0,080542 & 0,532097 \\
\hline Mogi-Mirim & 0,242095 & 0,171656 & 0,070439 & 0,528078 \\
\hline Guaratingueta & 0,177504 & 0,200793 & 0,023289 & 0,509290 \\
\hline
\end{tabular}

Fonte: Elaboração própria.

reduzido, na prática, pode ser considerada menos dispersa do que outra área um pouco menos fragmentada, porém com integração mais intensa destas áreas.

Neste sentido, adicionou-se o grau de dispersão, através de um indicador dos movimentos pendulares, para mensurar a dimensão da integração das aglomerações urbanas. Assim, foi utilizada uma composição de dois indicadores de integração: a proporção de movimentos pendulares internos à aglomeração urbana com des- 
tino não polarizado na sede; e a proporção de movimentos pendulares pelo total da população. O primeiro refere-se ao padrão e direção dos movimentos, sendo que aquelas aglomerações urbanas que possuem movimentos pendulares menos polarizados pela sede foram consideradas as que possuem um modelo de urbanização mais disperso. No segundo caso, a proporção de movimentos pendulares pelo total da população serve como parâmetro de padronização, uma vez que a importância dos movimentos com direção à sede dependerá da relevância que eles possuem no contexto do total da aglomeração urbana.

O procedimento foi realizado para cada uma das 37 aglomerações e considerou, portanto, as proporções de movimentos pendulares com destino à sede (considerando-se os menores valores aqueles mais representativos da dispersão urbana), ponderando-se pela intensidade do total de movimentos pendulares em relação à população total. Assim, com os valores padronizados, produziu-se uma escala de 0 a 1 , em que os valores mais próximos de zero correspondem à maior dispersão urbana.

A ponderação com base na proporção dos movimentos pendulares pela população total da aglomeração urbana foi importante para relativizar as situações em que os movimentos em direção à sede eram muito representativos, embora sua importância fosse pequena em relação ao total da população da aglomeração. Dessa forma, mesmo nas aglomerações onde a proporção de movimentos em direção à sede era relativamente baixa (como no caso de Vitória), a ponderação fez com que o indicador fosse mais significativo do que em outras onde os movimentos em direção à sede eram mais elevados (como na de Ribeirão Preto), já que neste último o peso dos movimentos pendulares em relação à população total era muito menos expressivo.

\section{Resultados: considerações sobre a análise comparativa da forma urbana}

O conjunto de dimensões leva em consideração variáveis demográficas e espaciais para entender a forma urbana e caracterizar a dispersão. Assim, para a composição do índice de dispersão urbana, foi utilizada uma média aritmética dos indicadores de cada dimensão, pois não haveria razões para atribuir um peso maior para algumas das dimensões em termos do que se pode dizer da dispersão urbana. A Tabela 4 sumariza cada uma das dimensões e apresenta o indicador de dispersão urbana derivado da combinação das dimensões consideradas.

O resultado da composição destes indicadores deverá oferecer subsídios para analisar, de forma comparativa, em que medida uma aglomeração urbana pode ser caracterizada como mais ou menos dispersa, independentemente do tamanho

FIGURA 8

Diagrama ilustrativo da metodologia de cálculo do indicador de centralidade
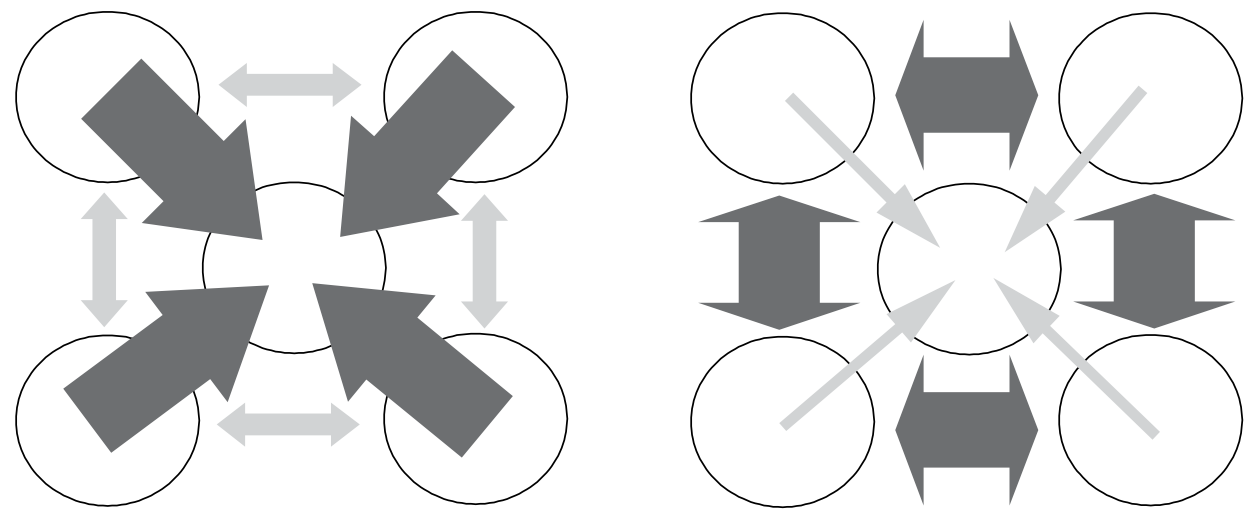
TABELA 4

Indicadores de densidade, fragmentação, linearidade, centralidade e dispersão e posto ocupado pela aglomeração no ranking

Aglomerações urbanas brasileiras - $\mathbf{2 0 0 0}$

\begin{tabular}{|c|c|c|c|c|c|c|c|c|c|c|}
\hline \multirow{2}{*}{$\begin{array}{c}\text { Aglomerações } \\
\text { urbanas }\end{array}$} & \multicolumn{2}{|c|}{ Densidade } & \multicolumn{2}{|c|}{ Fragmentação } & \multicolumn{2}{|c|}{ Linearidade } & \multicolumn{2}{|c|}{ Centralização } & \multicolumn{2}{|c|}{ Dispersão } \\
\hline & Indicador & Posto & Indicador & Posto & Indicador & Posto & Indicador & Posto & Indicador & Posto \\
\hline São Paulo & 0,22441 & 36 & 0,55188 & 35 & 0,59755 & 8 & 0,16402 & 17 & 0,38447 & 36 \\
\hline Salvador & 0,26499 & 35 & 0,68718 & 16 & 0,53841 & 24 & 0,30058 & 4 & $F_{0,44779}$ & 28 \\
\hline Belo Horizonte & 0,47156 & 29 & 0,65475 & 23 & 0,53657 & 27 & 0,08393 & 29 & $F_{0,43670}$ & 31 \\
\hline Brasília & 0,64495 & 8 & 0,76049 & 1 & 0,58114 & 11 & 0,08125 & 30 & $F_{0,51696}$ & 8 \\
\hline Curitiba & 0,50934 & 23 & 0,75326 & 5 & 0,54551 & 19 & 0,07321 & 32 & $F_{0,47033}$ & 18 \\
\hline Recife & 0,38266 & 30 & 0,60601 & 30 & 0,57910 & 12 & 0,07078 & 33 & $F_{0,40964}$ & 34 \\
\hline Porto Alegre & 0,47688 & 28 & 0,68555 & 17 & 0,59791 & 7 & 0,11971 & 23 & $F_{0,47001}$ & 19 \\
\hline São Luís & 0,48408 & 26 & 0,67359 & 20 & 0,51434 & 36 & 0,12003 & 22 & 0,44801 & 27 \\
\hline Maceió & 0,36967 & 31 & 0,66396 & 22 & 0,51690 & 35 & 0,18326 & 12 & 0,43345 & 33 \\
\hline Natal & 0,33465 & 32 & 0,74589 & 8 & 0,54794 & 18 & 0,11277 & 24 & 0,43532 & 32 \\
\hline João Pessoa & 0,48009 & 27 & 0,63982 & 24 & 0,54099 & 23 & 0,13733 & 20 & 0,44956 & 26 \\
\hline São José dos Campos & 0,63034 & 9 & 0,67637 & 19 & 0,60508 & 4 & 0,29092 & 6 & 0,55068 & 4 \\
\hline Ribeirão Preto & 0,53713 & 20 & 0,70592 & 14 & 0,60296 & 5 & 0,16496 & 16 & 0,50274 & 12 \\
\hline Sorocaba & 0,57631 & 12 & 0,67075 & 21 & 0,51815 & 34 & 0,20669 & 10 & 0,49298 & 16 \\
\hline Aracaju & 0,68414 & 4 & 0,54236 & 36 & 0,53782 & 26 & 0,06201 & 36 & 0,45658 & 25 \\
\hline Jundiaí & 0,56192 & 14 & 0,62104 & 27 & 0,55571 & 16 & 0,08992 & 28 & 0,45715 & 24 \\
\hline Florianópolis & 0,65224 & 6 & 0,74103 & 9 & 0,58546 & 10 & 0,07797 & 31 & 0,51418 & 10 \\
\hline Maringá & 0,01202 & 37 & 0,75407 & 3 & 0,53472 & 29 & 0,06310 & 35 & 0,34098 & 37 \\
\hline Vitória & 0,59490 & 10 & 0,57307 & 34 & 0,59065 & 9 & 0,09403 & 27 & 0,46316 & 23 \\
\hline Volta Redonda & 0,57166 & 13 & 0,73000 & 11 & 0,55139 & 17 & 0,14635 & 19 & 0,49985 & 13 \\
\hline Blumenau & 0,69802 & 2 & 0,70668 & 13 & 0,62394 & 3 & 0,24552 & 8 & 0,56854 & 1 \\
\hline Ipatinga & 0,58543 & 11 & 0,70988 & 12 & 0,54171 & 21 & 0,15514 & 18 & 0,49804 & 15 \\
\hline Criciúma & 0,68656 & 3 & 0,63325 & 25 & 0,52320 & 33 & 0,17274 & 13 & 0,50394 & 11 \\
\hline Itajaí & 0,64718 & 7 & 0,62003 & 29 & 0,57261 & 13 & 0,26382 & 7 & 0,52591 & 6 \\
\hline Cabo Frio & 0,71780 & 1 & 0,59788 & 31 & 0,53210 & 31 & 0,21717 & 9 & 0,51624 & 9 \\
\hline Mogi-Mirim & 0,51595 & 22 & 0,75271 & 6 & 0,52808 & 32 & 0,30267 & 3 & 0,52485 & 7 \\
\hline Guaratingueta & 0,55924 & 15 & 0,75355 & 4 & 0,50929 & 37 & 0,29877 & 5 & 0,53021 & 5 \\
\hline
\end{tabular}

Fonte: Elaboração própria.

da sua população. Segundo Lopez e Hynes (2003, p. 331), áreas metropolitanas com grande volume populacional não deveriam ser classificadas como mais dispersas simplesmente por abrangerem uma extensão maior do espaço. Assim, mesmo que determinada região seja 10 ou 20 vezes maior do que outra, ambas podem ter padrões similares e, por isso, deveriam ter indicadores de dispersão similares. Enfim, é preciso distinguir grandes extensões urbanas com o grau de dispersão considerado aqui através das dimensões e da síntese destas dimensões.

A Figura 9 mostra como o indicador construído satisfaz esse pressuposto, pois 
a AU de São Paulo - a despeito de seu volume populacional muito maior - apresenta um indicador de dispersão próximo das AUs de Belém, Recife ou ainda de Maringá. Afinal, a dispersão urbana não diz respeito ao tamanho populacional da aglomeração, pois, se assim fosse, não haveria parâmetros de comparação entre situações como São Paulo e as demais aglomerações urbanas.

Pode-se dizer que o indicador de dispersão urbana, embora não tenha esgotado as dimensões na análise da forma urbana, buscou cobrir as principais dimensões mencionadas pela literatura internacional referente ao estudo do urban sprawl. A relativa fragilidade das informações utilizadas, com base principalmente nos dados censitários, é compensada pela sua abrangência e uniformidade, permitindo construir um conjunto de indicadores para todas as aglomerações urbanas brasileiras. É evidente que refinamentos e detalhamentos posteriores, a partir de estudos de caso específicos, podem trazer elementos empíricos que uma análise nesta escala não é capaz de dar conta.
O indicador sintético procurou captar as dimensões da dispersão urbana e permitiu classificar as aglomerações urbanas a partir de um critério geral, sem levar em conta características particulares de cada aglomeração. O tamanho da população, ao contrário do que parece, não possui uma correlação positiva com o grau de dispersão urbana de uma região, de modo que a dispersão urbana não depende diretamente de um grande volume populacional. O caso da AU de São Paulo explicita essa condição do indicador, pois é um exemplo de que é possível mensurar a dispersão urbana sem que a desproporcional extensão urbana ou a população pesem na análise de forma determinante.

Claro que suas dimensões tornam-se um importante desafio para a gestão de políticas públicas, mas, em termos do processo de dispersão urbana, existem aglomerações que merecem especial atenção, pois as tendências do processo de urbanização recente não favorecem a reprodução do padrão de urbanização experimentado por São Paulo.

FIGURA 9

Indicador de dispersão urbana e população total

Aglomerações urbanas brasileiras - 2000

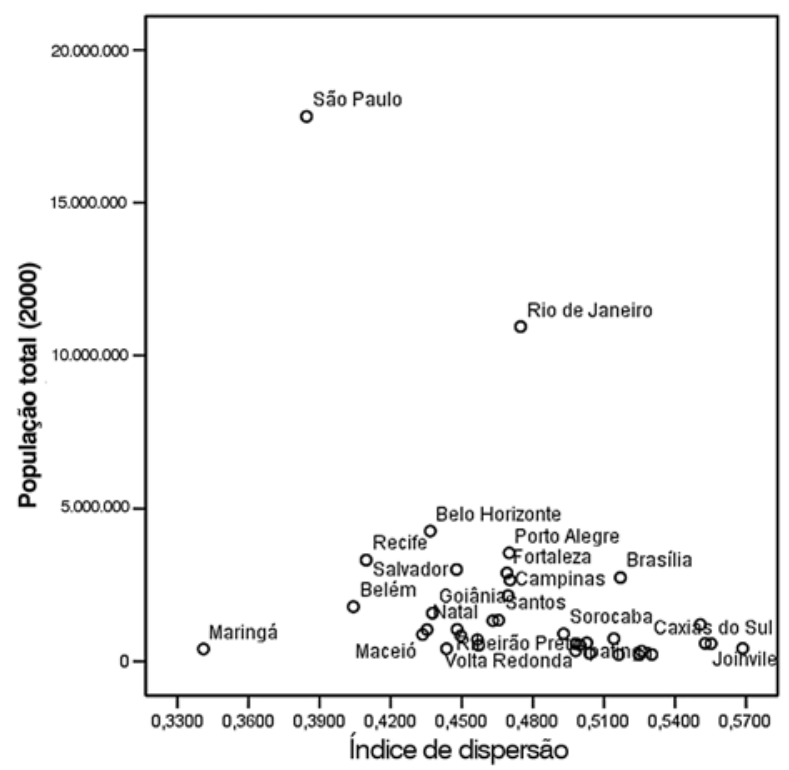

Fonte: IBGE. Censo Demográfico 2000 e dados do autor. 
Isso se deve, entre outras coisas, à mudança nos paradigmas de desenvolvimento social e urbano, que favorecem a desconexão das esferas de ação social, transformando o espaço intra-urbano em cenário de ações individualizadas, onde a racionalidade das ações pauta-se pela dimensão do risco social. A fragmentação dos espaços dentro das aglomerações urbanas torna-se cada vez mais uma forma de se defender diante dos riscos sociais na vida cotidiana e estaria refletindo a fragmentação da sociedade contemporânea (BAUMAN, 2007).
Como pode ser visto na Figura 10, as aglomerações urbanas mais dispersas encontram-se na porção sul-sudeste do país, com exceção do caso da AU de Brasília. Aquelas localizadas nas Regiões Norte e Nordeste estão todas entre as mais compactas, com exceção da AU de Fortaleza, que se coloca no grupo intermediário. Provavelmente isso possa ser explicado por características regionais de integração econômica, ampliação das tecnologias de transportes, ou ainda pela maior inserção no processo de globalização. Independente-

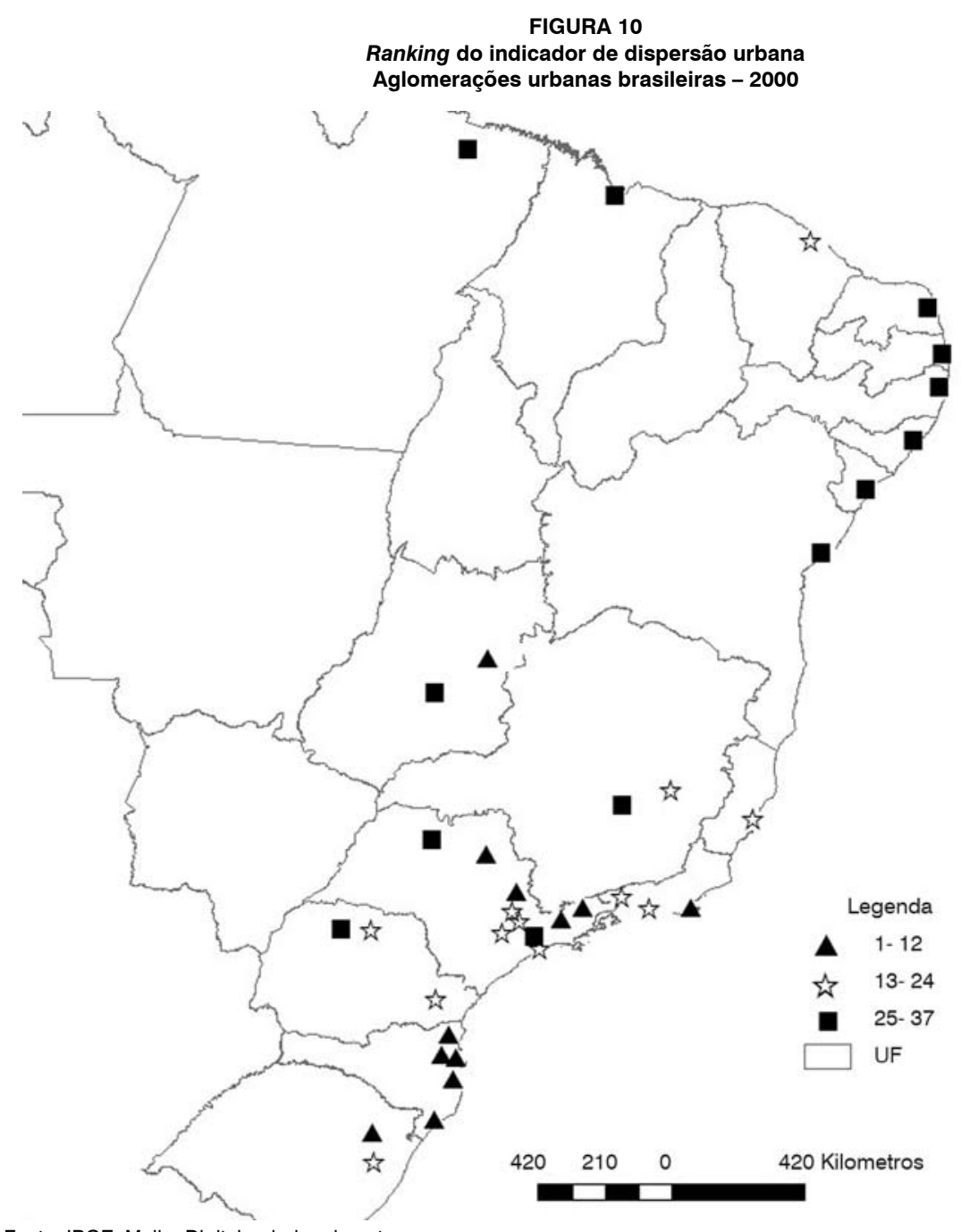

Fonte: IBGE. Malha Digital e dados do autor. 
mente da resposta, parece ser uma evidência importante a ser investigada, após esse primeiro esforço de análise comparativa.

Outro fator que deve ser considerado em futuras pesquisas refere-se à redução do padrão dicotômico centro-periferia como paradigma explicativo do processo de urbanização recente, uma vez que os fluxos de movimentos pendulares caracterizam um mosaico de situações distintas em cada uma das aglomerações urbanas e, sobretudo, porque a partir desse indicador pode-se perceber que os movimentos intraaglomerações urbanas não são, em todos os casos, predominantemente direcionados para a sede ou núcleo da aglomeração. Ou seja, existem aglomerações urbanas onde os deslocamentos de trabalho ou estudo se dão de forma difusa entre seus diversos municípios.

Em relação ao impacto ambiental da dispersão urbana, a literatura aponta para uma estreita relação entre as áreas urbanas mais dispersas e uma maior utilização de veículos automotores. Causa e efeito do processo de dispersão urbana, o uso e a expansão dos transportes automotores, sobretudo de uso particular, possuem impactos relevantes em termos da qualidade de vida da população nos principais centros urbanos, tais como congestionamentos, acidentes, incidência de atropelamentos e óbitos, além da poluição atmosférica e todas as suas conseqüências.

A partir dos indicadores de dispersão urbana para as aglomerações brasileiras, encontrou-se uma correlação negativa com a proporção de domićlios com pelo menos um automóvel de uso particular. Ou seja, quanto menor o ranking da aglomeração urbana (mais dispersa), maior a proporção de domicílios com pelo menos um automóvel de uso particular. Esse resultado era esperado, uma vez que a literatura já apontava para essa tendência, o que, inclusive, parece ser óbvio. Se uma região possui uma dispersão urbana maior, a necessidade de deslocamento e meios de transporte também deveria ser maior.

Claro que a variável renda tem um papel importante nessa relação, mas a mesma correlação negativa é encontrada em todas as classes de rendimentos per capita domiciliar. Desde para os domicílios com renda per capita inferior a meio salário mínimo até para aqueles com mais de dois salários mínimos por pessoa, a correlação se mantém significativa. Como se pode perceber através da Figura 11, as aglomerações urbanas mais dispersas possuem uma proporção maior de automóveis de uso particular, independentemente das classes de renda domiciliar.

Assim, é possível dizer que a medida de dispersão urbana é coerente e análises podem ser realizadas considerando outras relações. Como já exposto, o estudo mais detalhado sobre algumas aglomerações urbanas específicas pode trazer mais subsídios para o aprimoramento do indicador, tanto incluindo novas dimensões como qualificando melhor o processo. Uma análise comparativa de uma mesma região em termos temporais pode servir para indicar a intensidade em que o fenômeno ocorre e quais os impactos causados pela dispersão urbana à medida que se avança no tempo. Da mesma maneira, uma análise comparativa entre duas aglomerações permitiria um maior detalhamento dos processos que condicionam as distinções na forma.

Merece atenção o fato de que, se, por um lado, a análise comparativa com o uso de indicadores reduz a capacidade de analisar os processos condicionantes da urbanização contemporânea, por outro, permite identificar áreas prioritárias para a análise detalhada. Isso porque, segundo a literatura internacional, há uma associação significativa de efeitos negativos desse modelo de urbanização mais disperso e fragmentado, que se consolidou a partir da segunda metade do século 20. Entre os aspectos sociais relacionados à dispersão urbana, encontram-se a elevação dos custos sociais para a oferta de serviços públicos (como abastecimento de água, coleta de lixo e tratamento de esgoto) e o potencial aumento da dependência pelo uso de transportes automotores, pois ambos estariam condicionados pela maior ou menor dispersão da rede urbana.

Portanto, a urbanização sustentável, relacionada à capacidade de otimizar o uso 
FIGURA 11

Ranking de dispersão urbana versus proporção de domicílios com pelo menos um automóvel de uso particular, segundo classes de renda

Aglomerações urbanas brasileiras $\mathbf{- 2 0 0 0}$
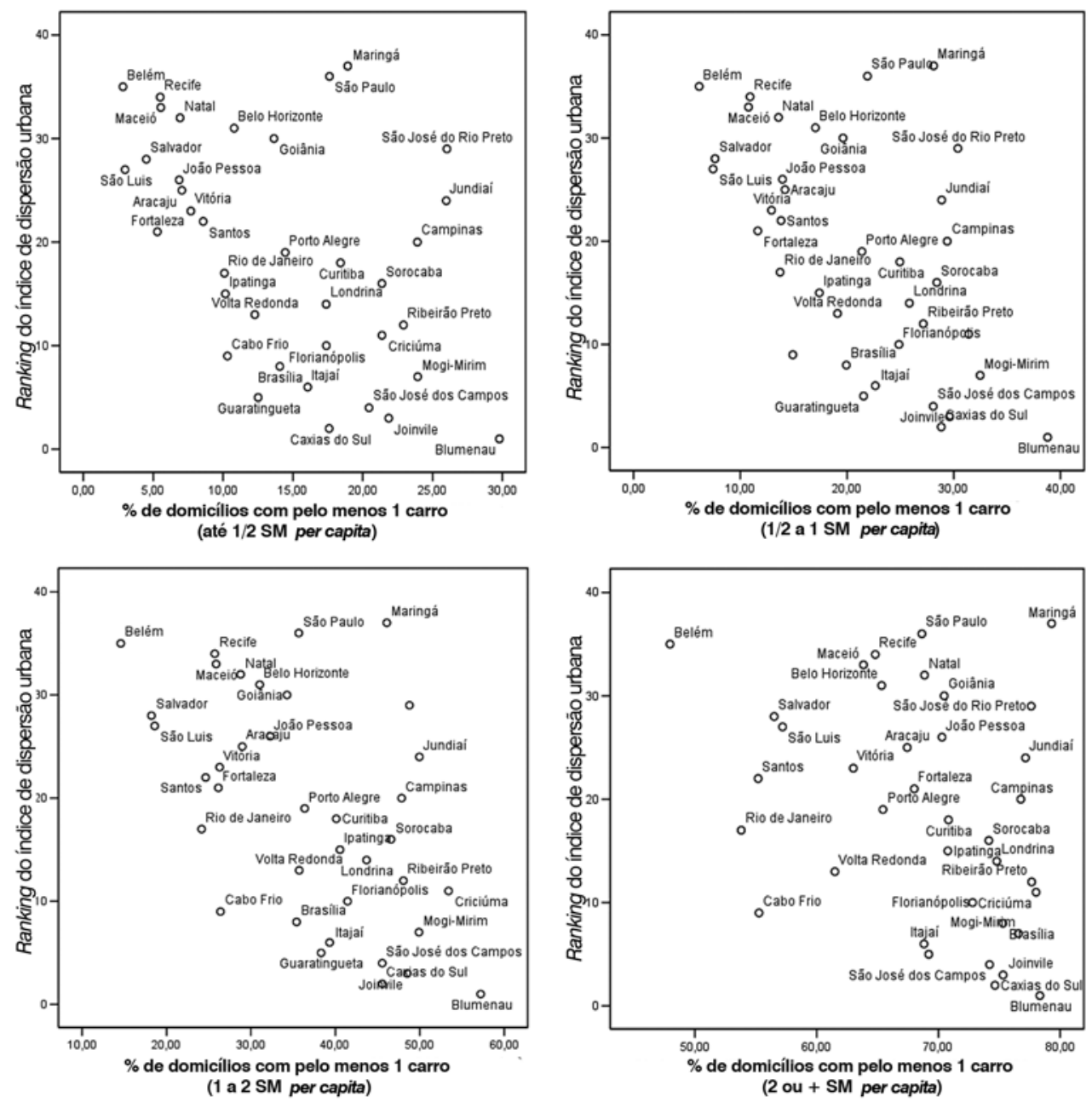

Fonte: IBGE. Censo Demográfico 2000 e dados do autor.

e a ocupação dos espaços urbanos, deverá cada vez mais considerar as relações do espaço vivido na experiência metropolitana e a construção social do espaço. É preciso entender as relações e dinâmicas internas às aglomerações urbanas, superando a dicotomia centro-periferia para poder compreender o papel das aglomerações urbanas contemporâneas e suas formas, dado que serão estes os potenciais pontos de tensão da urbanização mundial e brasileira nos próximos anos (UNFPA, 2007,

p.76). De certa forma, pode-se pensar que o planejamento e ordenamento territorial deverão considerar as conseqüências da mudança de um padrão denso para uma tendência de dispersão urbana. Portanto, incorporar a dimensão espacial como uma das variáveis explicativas dos processos sociais que se constituem nessas aglomerações não apenas contribuirá para padrões de urbanização mais sustentáveis, mas também será fundamental para entender a sociedade urbana. 
Em termos das mudanças ambientais, o processo de implosão-explosão urbana (LEFEBVRE, 1999) estará relacionado aos novos padrões de vida e às novas formas de consumo do espaço dentro destas áreas urbanas. Os efeitos serão sentidos em escalas locais, regionais e até mesmo globais, pois a dispersão urbana relaciona-se intimamente com as mudanças na vida cotidiana e as

\section{Referências bibliográficas}

ANGEL, S. Measuring global sprawl: the spatial structure of the planet's urban landscape, 2006. Mimeografado.

ANGEL, S.; SHEPPARD, S. C.; CIVCO, D. L. The dynamics of global urban expansion. Washington DC, Transport and Urban Development Department, The World Bank, 2005.

ARCGIS 9.0. Environmental Systems Research Institute, Inc. (ESRI).

BATTY, M.; XIE, Y.; SUN, Z. The dynamics of urban sprawl. London, Center for Advanced Spatial Analysis (CASA), University College London, 1999 (CASA Working Papers Series, n.15). Disponível em: <http://www.casa.ucl. ac.uk/publications/workingpapers.asp $>$. Acesso em: out. 2005.

BAUMAN, Z. Tempos líquidos. Jorge Zahar Editor, 2007.

$\mathrm{CHIN}, \mathrm{N}$. Unearthing the roots of urban sprawl: a critical analysis of form, function and methodology. London, Center for Advanced Spatial Analysis (CASA) University College London, 2002 (CASA Working Papers Series, n.47). Disponível em: <http://www. casa.ucl.ac.uk/publications/workingpapers. asp >. Acesso em: out. 2005.

CUTSINGER, J.; GALSTER, G.; WOLMAN, $\mathrm{H}_{\text {.; }}$ HANSON, R.; TOWNS, D. Verifying the multi-dimensional nature of metropolitan land use: advancing the understanding and measurement of sprawl. Journal of Urban Affairs, Urban Affairs Association, vol. 27, n.3, p. 235-259, 2005.

FARIA, V. Cinqüenta anos de urbanização no Brasil. Revista Novos Estudos CEBRAP, São Paulo, n.29, p. 98-119, 1991. representações do risco social inerentes a essas mudanças. Assim, se a fuga dos riscos dentro dos contextos urbanos delineará o contorno da urbanização contemporânea e estará fortemente vinculada ao que desejamos como qualidade de vida urbana, cabe buscar novo instrumental metodológico para abordar as contradições da urbanização na sociedade moderna.

GALSTER, G.; HANSON, R.; WOLMAN, H.; COLEMAN, S.; FREIHAGE, J. Wrestling sprawl to the ground: defining and measuring an elusive concept. Housing Policy Debate, Fannie Mae Foundation, v.12, issue 4, p. 681-717, 2001.

GARCIA, R. A.; MATOS, R. Densidade populacional urbana e fluxos migratórios: um modelo de estimação da área urbana dos municípios brasileiros. In: ENCONTRO NACIONAL SOBRE MIGRAÇÃO, IV. Anais... Rio de Janeiro, Abep, 2005.

GIDDENS, A. As conseqüências da modernidade. São Paulo: Ed. Unesp, 1991.

I PEA / I B GE / NE S UR - U N I C A M P. Características e tendências da rede urbana no Brasil. Campinas: Instituto de Economia, Unicamp, 2000.

INDOVINA, F. La cittá diffusa. Venezia: Daest Ed., 1990.

KIEFER, M. J. Suburbia and its discontents. Harvard Design Magazine, n.19, p.1-5, 2003.

LEFEBVRE, H. A revolução urbana. Belo Horizonte: Editora UFMG, 1999.

LOPEZ, R.; HYNES, H. P. Sprawl in the 1990s: measurement, distribution and trends. Urban Affairs Review, v.38, n.3, p. 325-355, 2003.

MEADOWS, D.H. So what can we do - really do - about sprawl. Sprawl articles, Sierra Club, 2003. Disponível em: <http://www. sierraclub.org/sprawl/articles/meadows3. asp >. Acesso em: jun. 2005. 
OJIMA, R. Análise comparativa da dispersão urbana nas aglomerações urbanas brasileiras: elementos teóricos e metodológicos para o planejamento urbano e ambiental. Tese (doutorado). Campinas, Unicamp, 2007.

RICHARDSON, H. W.; CHANG-HEE, C. B. (Eds.). Urban sprawl in Western Europe and the United States. England: Ashgate Publishing Limited, 2004.

ROCA, J.; BURNS, M. C.; CARRERAS, J. M. Monitoring urban sprawl around Barcelona's Metropolitan Area with the aid of satellite imagery. In: XXth ISPRS CONGRESS. Istanbul, Turkey, 12-23 July 2004. Disponível em: <http://www.isprs.org/istanbul2004/ comm1/comm1.html $>$. Acesso em: jan. 2006.

SCOTT, A.J.; AGNEW, J.; SOJA, E.W.; STORPER, M. Cidades-regiões globais. Espaço e Debates, no 41, p.11-25, 2001.

SIERRA CLUB. New research on population, suburban sprawl and smart growth, 2003. Disponível em: <http://www.sierraclub.org/ sprawl/population/whitepaper.asp $>$. Acesso em nov. 2006.

SOJA, E. Geografias pós-modernas: a reafirmação do espaço na teoria social crítica. Rio de Janeiro: Zahar editores, 1993.

TORRENS, P. M.; ALBERTI, M. Measuring sprawl. London, University College London, Center for Advanced Spatial Analysis CASA, 2002 (CASA Working Papers Series, n.27). Disponível em: <http://www.casa.ucl. ac.uk/publications/workingpapers.asp $>$. Acesso em: out. 2005.

UNFPA - United Nations Population Fund. State of world population 2007: unleashing the potencial of urban growth. New York: UNFPA, 2007.

VEIGA, D. Notas para una agenda de investigación sobre procesos emergentes en la sociedad urbana. In: RIBEIRO, A. C. (Org.). Repensando a experiência urbana da América Latina: questões, conceitos e valores. Buenos Aires: CLACSO, 2000, p. 19-33.

VILLAÇA, F. Efeitos do espaço sobre o social na metrópole brasileira. In: SOUZA, M. A. A.; LINS, S. C.; SANTOS, M. P. C.; SANTOS, M. C. Metrópole e globalização: conhecendo a cidade de São Paulo. São Paulo: Ed. Cedesp, 1999, p. 221-236.

\section{Resumen}

Dimensiones de la urbanización dispersa y propuesta metodológica para estudios comparativos: un abordaje socio-espacial en aglomeraciones urbanas brasileñas

Este artículo pretende abordar la urbanización brasileña bajo una perspectiva comparativa, a partir de la construcción de un Indicador de Dispersión Urbana, con el objetivo de contribuir con el análisis de los desafíos para una urbanización sustentable. Se trata de la búsqueda de evidencias que confirmen las proposiciones teóricas de una nueva etapa del desarrollo de la sociedad moderna (riesgos socioambientales) y los desafíos para el análisis de la relación población-ambiente en los contextos urbanos. Para componer un indicador sintético de dispersión urbana para las aglomeraciones urbanas brasileñas, fueron consideradas las siguientes dimensiones sociales y espaciales: densidad, fragmentación, orientación y centralidad. Los resultados obtenidos fueron compatibles con las evidencias apuntadas por la literatura internacional, exponiendo los nuevos desafíos para la planificación urbana y ambiental.

Palabras-clave: Crecimiento urbano. Planificación urbana. Medio ambiente. 


\begin{abstract}
The dimensions of urban sprawl and a methodological proposal for comparative studies: a social-spatial approach in Brazilian urban agglomerations

The goal of this paper is to further our understanding of the challenges for sustainable urbanization. This objective required both theoretical and methodological investments in the search for evidence which could confirm the theoretical proposal of a new stage of the development of modern society (social and environmental risks) and the challenges involved in analyzing the population-environment relationship in urban contexts. The index that was developed considered four social and spatial dimensions in order to compose a synthetic index of urban dispersion for Brazilian urban agglomerations: Density, Fragmentation, Linearity and Centrality. Results are compatible with the evidence presented in the international literature and suggest new challenges for urban and environmental planning.
\end{abstract}

Keywords: Urban growth. Urban planning. Environment.

Recebido para publicação em 24/08/2007. Aceito para publicação em 12/11/2007. 